\title{
Posterior interosseous nerve palsy caused by lipoma: A case report
}

\author{
Amanda Murphy BSc, Jason Williams MD FRCSC
}

A Murphy, J Williams. Posterior interosseous nerve palsy caused by lipoma: A case report. Can J Plast Surg 2009;17(4):e42-e44.

Lipomas are benign soft tissue neoplasms that occur commonly in subcutaneous tissue. In rare instances they can occur in deeper planes. When occurring in the proximal forearm they can compress the posterior interosseous branch of the radial nerve resulting in an insidious onset of weakness of digital extensor muscles. A case of posterior interosseous nerve palsy from lipoma in a 58-year-old man in presented.

Key Words: Forearm; Lipoma; Posterior interosseous nerve palsy

$\mathrm{T}$ he radial nerve originates from the posterior cord of the brachial plexus with contributions from C5, C6, C7, C8 and T1. It enters the forearm just deep to the brachioradialis muscle and bifurcates into superficial and deep branches. The superficial branch provides sensory innervation to the skin on the dorsolateral surface of the hand. The deep branch becomes the posterior interosseous nerve (PIN) after emerging between the two heads of the supinator muscle. It supplies motor innervation to the muscles in the posterior compartment of the forearm.

First described in the literature by Richmond in 1953 (1), lipomas of the proximal forearm are an uncommon cause of PIN compression. Lipomas are benign soft tissue tumours that are typically indolent in nature and rarely cause symptoms of nerve compression (2). Patients with PIN palsy caused by compression from a lipoma typically describe weakness of digital extension evolving over a period of several months (3). To date, fewer than 40 cases have been reported in English

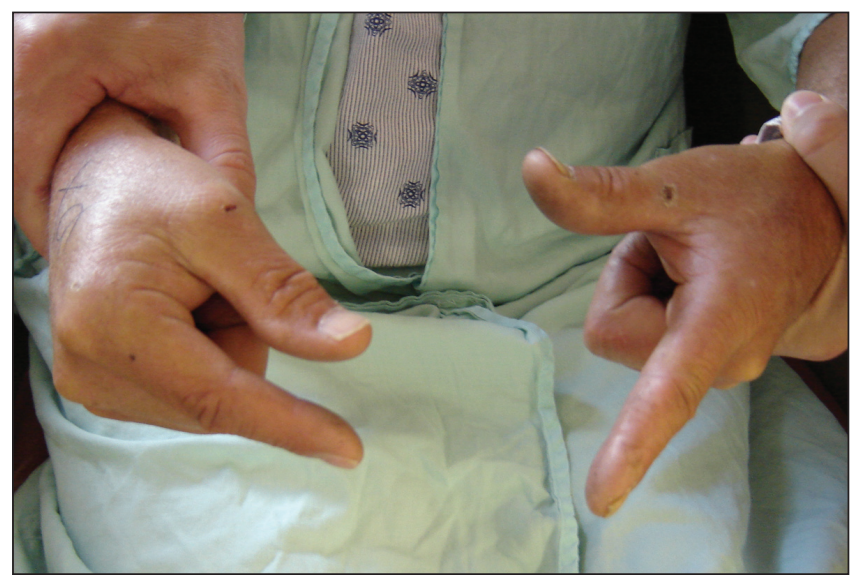

Figure 1) A 58-year-old man with absence of independent extension of right index finger and thumb prior to surgical decompression of the posterior interosseous nerve from lipoma

\section{Une paralysie du nerf interosseux postérieur causée par un lipome : Un rapport de cas}

Les lipomes sont des néoplasmes bénins des tissus mous qui se produisent fréquemment dans les tissus sous-cutanés. Dans de rares cas, ils peuvent se manifester dans des plans plus profonds. Lorsqu'on les observe dans l'avantbras proximal, ils peuvent comprimer le rameau interosseux postérieur du nerf radial et provoquer l'apparition insidieuse d'une faiblesse des muscles extenseurs des doigts. Les auteurs présentent le cas d'un homme de 58 ans ayant une paralysie du nerf interosseux postérieur causée par un lipome.

literature. We present a case of PIN compression by lipoma in a 58-year-old man.

\section{CASE PRESENTATION}

A 58-year-old man presented with a one-year history of pain in his right dorsal forearm shortly followed by the inability to extend his right index finger. Physical examination demonstrated a palpable mass in the proximal forearm. There was absence of independent extension of the right index finger (Figure 1). Extension of the remaining right digits was weak but intact (Figure 2). The patient also exhibited slight weakness of right wrist extension when compared with the left. There was no sensory deficit. Magnetic resonance imaging revealed a large, intramuscular lipoma measuring $7.4 \mathrm{~cm}$ at its largest diameter, beginning at the elbow and extending distally (Figure 3).

Surgical exploration and PIN decompression was undertaken. A curvilinear incision was made in the proximal forearm over

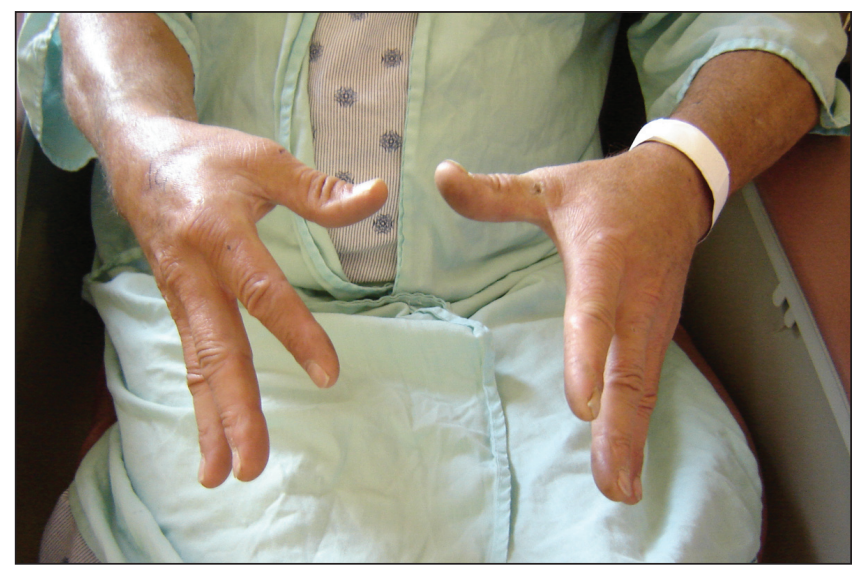

Figure 2) Same man demonstrating intact extension of remaining right digits

Dalhousie University, Halifax, Nova Scotia

Correspondence: Dr Jason Williams, Ste 4447, Halifax Infirmary, 1796 Summer Street, Halifax, Nova Scotia B3H 3 A7.

Telephone 902-473-6315, fax 902-473-6296, e-mail drjwilliams@gmail.com 


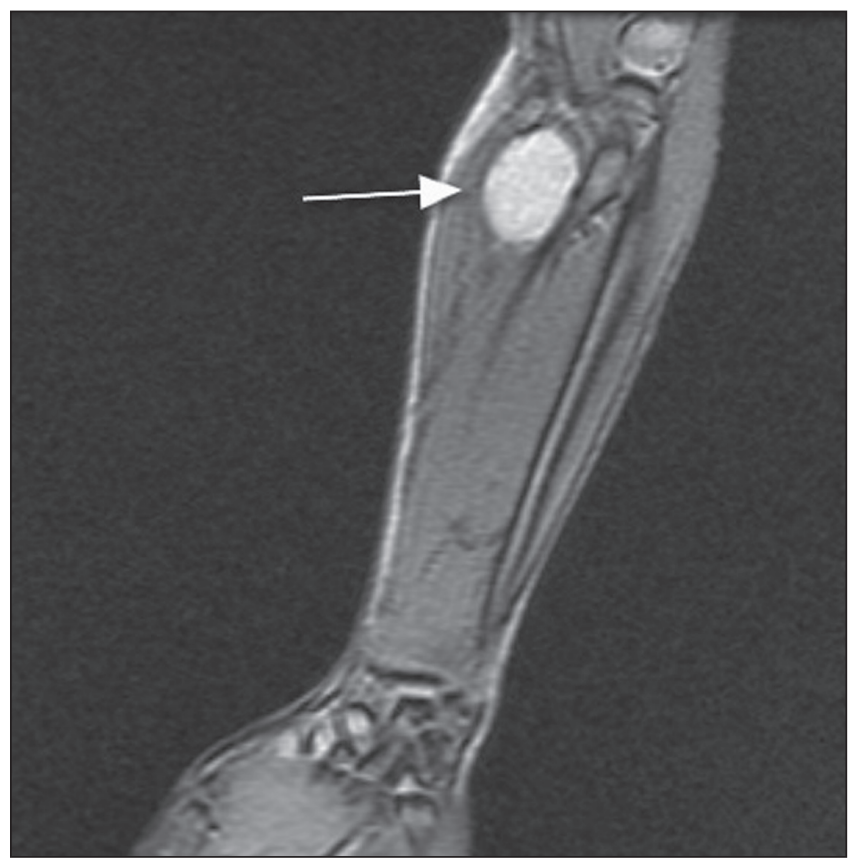

Figure 3) Magnetic resonance imaging revealing a large intramuscular lipoma of the right forearm (arrow)

the brachioradialis muscle where the mass could be appreciated. The incision was extended upward in a zig-zag fashion into the antecubital fossa. The brachioradialis muscle was exposed and reflected to reveal the tumour in the space below (Figure 4). The tumour was resected in one large segment with care taken to preserve the integrity of the superficial radial and posterior interosseous nerves. Following excision of the tumor, the wound was inspected. The nerves remained intact.

Gross examination of the tumour demonstrated a wellcircumscribed, $7.4 \mathrm{~cm} \times 4.2 \mathrm{~cm}$ yellow mass clinically consistent with a lipoma. Pathological findings were consistent with lipoma. There was no evidence of malignant change.

The patient's postoperative course was uneventful. At a sixmonth follow-up the patient demonstrated improved extension of his right thumb and index finger. He was able to lift both digits against gravity. However, he was unable to oppose any resistance.

\section{DISCUSSION}

To date, there have been limited reports of PIN compression caused by lipoma. While lipomas themselves occur commonly in subcutaneous tissue, it is rare to find them in deeper sites (3). Other causes of nontraumatic paralysis of the PIN include entrapment by the fibrous edge of the supinator muscle $(4,5)$, rheumatoid arthritis $(6,7)$ and neuralgic amyotrophy (8). Of these, entrapment by the supinator is by far most common (9).

Patients presenting with lipoma compression of the PIN will typically describe weakness of digital extension that is insidious in onset (3). Other symptoms that should alert the clinician of the possibility of PIN compression include persistent, severe pain radiating from the forearm into the neck and back, as well as a profound sense of heaviness of the involved arm (10). Detection of a mass in the proximal forearm usually occurs only upon seeking medical attention (3), as was the case with our patient. The vast majority of patients do not suffer any sensory

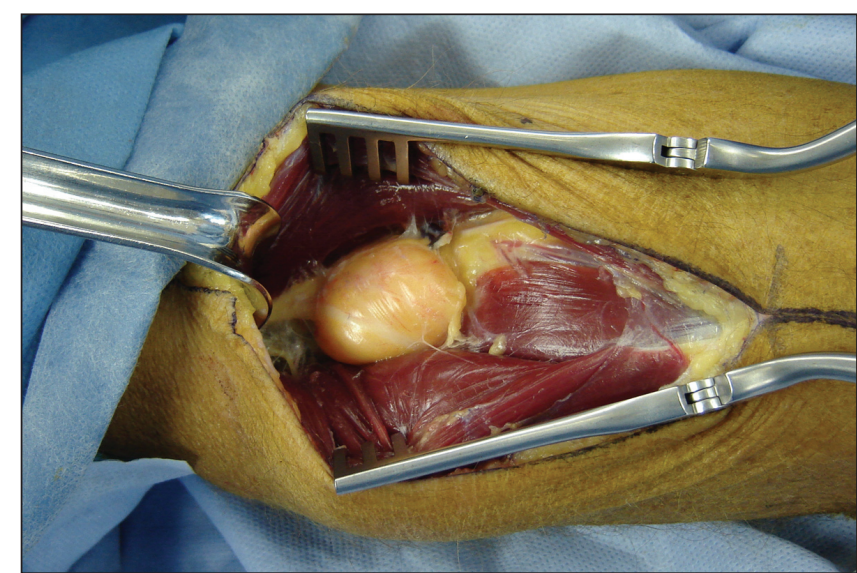

Figure 4) The brachioradialis muscle is reflected to expose a $7.4 \mathrm{~cm}$ $\times 4.2 \mathrm{~cm}$ lipoma compressing the posterior interosseous nerve

disturbance; however, occasionally there is combined involvement of the superficial radial nerve resulting in accompanied sensory deficit $(2,11,12)$.

Diagnosis is made on the basis of clinical findings and radiologic studies. Both x-ray and ultrasonographic studies can be useful in diagnosing PIN compression by lipoma. Magnetic resonance imaging, however, has proven most valuable in providing detailed soft tissue information as well as anatomical location $(9,13)$. Electromyography studies have also been used to identify the site of a nerve lesion (9).

Treatment of PIN palsy by lipoma is surgical decompression. Several approaches have been described in the literature. In the posterior approach, the supinator muscle is reached by dissection between extensor digitorum and extensor carpi radialis brevis, followed by division of the supinator to reveal the posterior interosseous nerve. When compared with the anterior approach, there is less depth of dissection resulting in a more rapid technique. However, retraction of the PIN required during excision of the tumour subjects this delicate structure to trauma. Results of the posterior approach were subsequently found to be unsatisfactory in a 2002 study by Fitzgerald et al (3). The anterior approach, first described by Henry in 1973 (14), involves dissection between brachioradialis and brachialis muscles. This allows for separation of the PIN under direct vision and is preferred to the posterior approach (3).

Time to follow-up varied among the studies examined; however, the majority of patients regained use of extensors one year following surgical decompression $(1,3,9,13)$. Early excision of lipomas compressing the PIN is recommended, with two years being the longest reported duration of symptoms to surgery that resulted in full recovery $(3,15)$. It is also important to ensure complete removal of the tumour because recurrence has been documented $(3,16)$.

\section{REFERENCES}

1. Richmond DA. Lipoma causing posterior interosseous nerve lesion. J Bone Joint Surg Br 1953;35-B:83.

2. Tzeng C-Y, Lee T-S, Chen I-C. Superficial radial nerve compression caused by a parosteal lipoma of proximal radius: A case report. J Hand Surg 2005;10:293-6.

3. Fitzgerald A, Anderson W, Hooper G. Posterior interosseous nerve palsy due to parosteal lipoma. J Hand Surg Br 2002;27:535-7.

4. Capener N. The vulnerability of the posterior interosseous nerve of the forearm: a case report and an anatomical study. J Bone Joint Surg Br 1966;48:770-3. 
5. Spinner M. The arcade of Frohse and its relationship to posterior interosseous nerve paralysis. J Bone Joint Surg Br 1968;50:809-12.

6. Marmor L, Lawrence JF, Dubois EL. Posterior interosseous nerve palsy due to rheumatoid arthritis. J Bone Joint Surg Am 1967:49:381-3.

7. White SH, Goodfellow JW, Mowat A. Posterior interosseous nerve palsy in rheumatoid arthritis. J Bone Joint Surg Br 1988;70:468-71.

8. Furusawa S, Hara T, Maehiro S, Shiba M, Kondo T. Neuralgic amyotrophy. Seikeigeka 1969;20:1286-90.

9. Hashizume H, Nishida K, Nanba Y, Shigeyama Y, Inoue H, Morito Y. Non-traumatic paralysis of the posterior interosseous nerve. J Bone Joint Surg Br 1996;78:771-6.

10. Effron CR, Beasley RW. Compression neuropathies in the upper limb and electrophysiologic studies. In: Thorne HC, ed. Grabb \&
Smith's Plastic Surgery. New York: Lippincott Williams \& Wilkins, 1997:830-3.

11. Lidor C, Lotem M, Hallel T. Parosteal lipoma of the proximal radius: A report of five cases. J Hand Surg 1992;17A:1095-7.

12. Moon N, Marmor L. Parosteal lipoma of proximal part of radius: Clinical entity with frequent radial nerve injury. J Bone Joint Surg 1964;46A:608-14.

13. Ganapathy K, Winston T, Sheshadri V. Posterior interosseous nerve palsy due to intermuscular lipoma. Surg Neurol 2006;65:495-6.

14. Henry AK. Extensile exposure, 2nd edn. Edinburgh: Churchill Livingstone, 1973:100-15.

15. Werner CO. Radial nerve paralysis and tumor. Clin Orthop Relat Res 1991;268:223-5.

16. Fleming RJ, Alpert M, Garcia A. Parosteal lipoma. AJR Am J Roentgenol 1962;87:1075-84. 